\title{
GARCÍA SAN JOSÉ, Daniel, La libertad de expresión 4.0 en el sistema del Convenio Europeo de Derechos Humanos, Ed. Tirant lo Blanch, Valencia, 2021, 268 páginas ISBN:978-84-1113-269-5
}

\author{
César A.Villegas Delgado
}

Universidad de Sevilla

cvillegas@us.es@0000-0003-0750-8352

Después del derecho a la vida y a la integridad física, la libertad de expresión quizás sea el más relevante de los derechos humanos. ¿Cuál es el significado de la libertad de expresión a comienzos del siglo XXI en un mundo dominado por el uso intensivo de internet y de las tecnologías punta? ¿Cuáles son su contenido y límites en sociedades donde se erosiona progresivamente la línea que separa lo público y lo privado? ¿Con qué mecanismos de protección contamos para preservarla de las amenazas que la acechan? A través del examen de los principios jurisprudenciales afirmados por el Tribunal europeo de derechos humanos conociendo sobre múltiples aspectos de la libertad de expresión en el contexto actual de los desarrollos tecnológicos -en particular, en conexión con internet-, el autor de esta monografía desarrolla una investigación de "microcirugía jurídica" con la que ofrece respuestas a estas preguntas.

La estructura de esta monografía es la siguiente: tras una introducción (págs. 11 a 65) en la que presenta el significado, alcance e interconexión entre los conceptos sociedad democrática y libertad de expresión 4.0 en el contexto europeo, con especial atención a las exigencias de pluralismo en los medios audiovisuales, el capítulo primero (págs. 66 a 101) está dedicado a la relevancia de internet como medio vehicular de la libertad de expresión 4.0 y la construcción jurisprudencial de los órganos garantes del sistema del Convenio europeo de derechos humanos al apreciar limitaciones en el ejercicio de esta libertad, como ocurre, por ejemplo, en supuestos de bloqueo del acceso a Internet impuesto a particulares. A pesar de su relevancia, la libertad de expresión garantizada en el artículo 10 del Convenio europeo no es un derecho absoluto, sino sometido a limitaciones en conexión con otros derechos y libertades protegidos en el sistema del Convenio europeo; en particular, en lo que hace al derecho al respeto de la vida privada y, más concretamente, los derechos al respeto de la propia imagen y reputación, así como a no sufrir difamación, protegidos, todos ellos, bajo el paraguas del artículo 8 del Convenio europeo.

En el capítulo segundo de esta monografía (págs. 101 a 141), el Profesor García San José, analiza cuestiones como las formas de injerencia en el disfrute del derecho a la vida privada y la necesidad de protegerlo frente a nuevas amenazas no previstas en el momento de la redacción de 
este instrumento internacional de protección de derechos humanos (véase Internet). Aun cuando para que el artículo 8 del Convenio europeo entre en juego, es jurisprudencia del Tribunal europeo verificar que dicho ataque sobre la reputación de una persona haya alcanzado un cierto umbral de gravedad, es posible constatar que este órgano judicial internacional se muestra particularmente flexible a la hora de estimar alcanzado dicho nivel en muy diversos contextos y situaciones, en particular, en relación con demandas por difamación presentadas por particulares con respecto a los comentarios ofensivo publicados en portales de Internet. Dado el relevante papel de la prensa en una sociedad democrática, debe realizarse un serio control europeo sobre restricciones en la libertad de expresión 4.0 que busca proteger los derechos de terceros, tomándose en cuenta aspectos tales como el nexo entre la declaración impugnada y la persona que demanda por difamación, su veracidad, así como la gravedad de las sanciones que se hayan impuesto a los periodistas o editores condenados por difamación o por ataque al honor y a la imagen de otras personas, la contribución a un debate público sobre una cuestión de interés general.

Una de las cuestiones centrales de esta monografía es la tratada en el capítulo tercero (págs. 143 a 193), en el que se ocupa de identificar aquellos principios extraíbles de la jurisprudencia europea para encontrar un equilibrio entre la libertad de expresión 4.0 y los derechos de terceros, como continuación y corolario del análisis desarrollado en el capítulo anterior. En este sentido, pueden mencionarse diversos factores que en opinión de este órgano determinan un justo equilibrio entre los distintos intereses en juego: la distinción entre declaraciones sobre hechos y juicios de valor; la eximente de la exceptio veritatis o capacidad de probar la veracidad de una afirmación; el papel y la condición de la persona que realiza la declaración impugnada; así como la naturaleza y gravedad de las medidas previstas en respuesta a una supuesta difamación. El Tribunal europeo considera indistintamente estos elementos en cada caso concreto que conoce sin que se trate de una lista exhaustiva, pues puede tomar en consideración otros elementos, en función de las circunstancias particulares de cada caso.

El cuarto y último capítulo de esta obra (págs. 195 a 249) se refiere al alcance de las restricciones por motivo de interés general y para la protección de los derechos de terceros en la libertad de expresión 4.0 a la luz de la jurisprudencia europea. Al respecto, el autor se interroga acerca de si son válidas y suficientes las respuestas que desde el Derecho europeo de protección de los derechos humanos se están dando frente a los desafíos que plantean los avances científicos y tecnológicos y que se reflejan en la que hemos llamado la libertad de expresión 4.0? La respuesta a esta pregunta, tras analizar la jurisprudencia europea relevante, es afirmativa siempre que se cumplan las que el autor de esta monografía denomina como las cuatro reglas de oro de la protección de la libertad de expresión 4.0: Primera regla de oro: los principios generales aplicables a las publicaciones fuera de línea también se aplican en línea. La segunda regla de oro: Internet requiere además unos principios particulares en razón a la naturaleza especialmente vulnerable de ciertas personas y los deberes y responsabilidades de los gestores de portales de Internet. La tercera regla de oro: el acceso a la información en Internet es un nuevo derecho 
implícito en la libertad de expresión 4.0. La cuarta regla de oro: la ética periodística no cobra un papel especialmente relevante tratándose de la libertad de expresión 4.0 en Internet.

Si se consolidan estas cuatro reglas de oro en la jurisprudencia europea en los próximos años, podremos afirmar con rotundidad-como hace el autor de este trabajo-que son válidas y suficientes las respuestas que desde el Derecho europeo de protección de los derechos humanos se están dando frente a los desafíos que plantean los avances científicos y tecnológicos para la libertad de expresión. A fin de cuentas, como recuerda el Profesor García San José concluyendo su obra, "nihil nobit sub solis. Los padres redactores del Convenio europeo optaron por un instrumento vivo, que debía perdurar en el tiempo (el pensamiento catedral tan denostado en el momento presente). Por ello, debía ser interpretado por sus órganos custodios -la antigua Comisión y el Tribunal europeo- a la luz de las condiciones de vida presentes en las sociedades europeas de cada época, no sólo considerando las que se daban en el momento en que este instrumento se concibió. Resulta difícil pensar que, al obrar así en 1950, aquellos insignes juristas tuvieran en mente con respecto a la libertad de expresión, los cambios que traerían Internet y las redes sociales; pero sin duda, acertaron en su elección; para nuestro bien y el de las generaciones futuras."

Se trata, por su actualidad y relevancia, de una obra de lectura recomendada para juristas, profesionales de los medios de comunicación, así como de interés para el público en general. 